\title{
Differential diagnosis between the primary total choroidal vascular atrophies
}

\author{
KIRSTI TAKKI \\ From the Department of Ophthalmology, University of Helsinki, Finland
}

Many descriptions of the primary chorio-retinal degenerations have been reported (Sosbry, Franceschetti, Joseph, and Davey, I952; Waardenburg, I 959; Waardenburg, Franceschetti, and Klein, r961, 1963; Franceschetti, François, and Babel, I963). Earlier diagnostic methods of distinguishing these disorders were limited to genetic investigation, general examination, objective ocular examination, functional ocular examination, and investigation of development (François, I958). Further histological (McCulloch, I969; Vogel, I 972) and fluorescein angiographic studies (Krill, Newell, and Chishti, I968; Amalric, I969; Hyvärinen, Maumenee, George, and Weinstein, I969) gave fresh insight into the nature of many of these conditions. A clear-cut classification of the choroidal atrophies based on fluorescein angiographic and functional studies was described by Krill and Archer (197I), but even this does not offer a precise method for differential diagnosis between the primary chorio-retinal degenerations in all cases.

In our earlier study (Simell and Takki, I973), a constant relationship between gyrate atrophy of the choroid and retina and hyperornithinaemia was found. This offers a new method of distinguishing gyrate atrophy from the other primary chorio-retinal atrophies.

\section{Material and methods}

In this study a comparison was made between the present data and those obtained from the patients with gyrate atrophy of the choroid and retina. The data of the patients with gyrate atrophy of the choroid and retina refer to the previous study (Takki, 1974).

Only two patients with choroideremia were found, the ophthalmological features of these patients agrecing with those of choroideremia patients described in the literature. These two patients with choroideremia and three with central regional total choroidal vascular atrophy (CRT) were included. The two patients with choroideremia and two with CRT were found in an examination of case histories from $196 \mathrm{r}$ to 1972 with clinical diagnosis of any primary chorio-retinal degeneration. The third case of CRT was referred to the author. The patients with choroideremia were first cousins. No other consanguinity was present. The characteristics of the patients are shown in Table I.

Table I Characteristics and plasma ornithine concentration in patients withchoroideremia and central regional total choroidal atrophy

\begin{tabular}{|c|c|c|c|c|}
\hline $\begin{array}{l}\text { Patient } \\
\text { no. }\end{array}$ & Diagnosis & Sex & $\begin{array}{l}\text { Age } \\
(y r s)\end{array}$ & $\begin{array}{l}\text { Plasma ornithine } \\
\text { concentration }(\mu M) *\end{array}$ \\
\hline I & Choroideremia & Male & 20 & $74 \cdot 9$ \\
\hline 2 & Choroideremia & Male & 37 & $82 \cdot 6$ \\
\hline 3 & CRT & Female & 40 & $63 \cdot 2$ \\
\hline 4 & CRT & Female & 68 & $63 \cdot 6$ \\
\hline 5 & CRT & Female & 76 & $75 \cdot 6$ \\
\hline
\end{tabular}

* Normal range (Soupart, 1962) $30-64 \mu \mathrm{M}$ 
Routine ophthalmological examination, with visual field studies, dark adaptation, colour vision, electroretinography, electro-oculogram, and fluorescein angiography of the fundus were performed as described earlier (Takki, I974). The amino-acids of plasma were quantitatively estimated as described in our previous study (Simell and Takki, I973), by the method of Spackman, Stein, and Moore (1958).

\section{Results}

FUNDUS FINDINGS

Gyrate atrophy of the choroid and retina

In the early stages of gyrate atrophy, sharply-defined atrophic areas of the fundus were

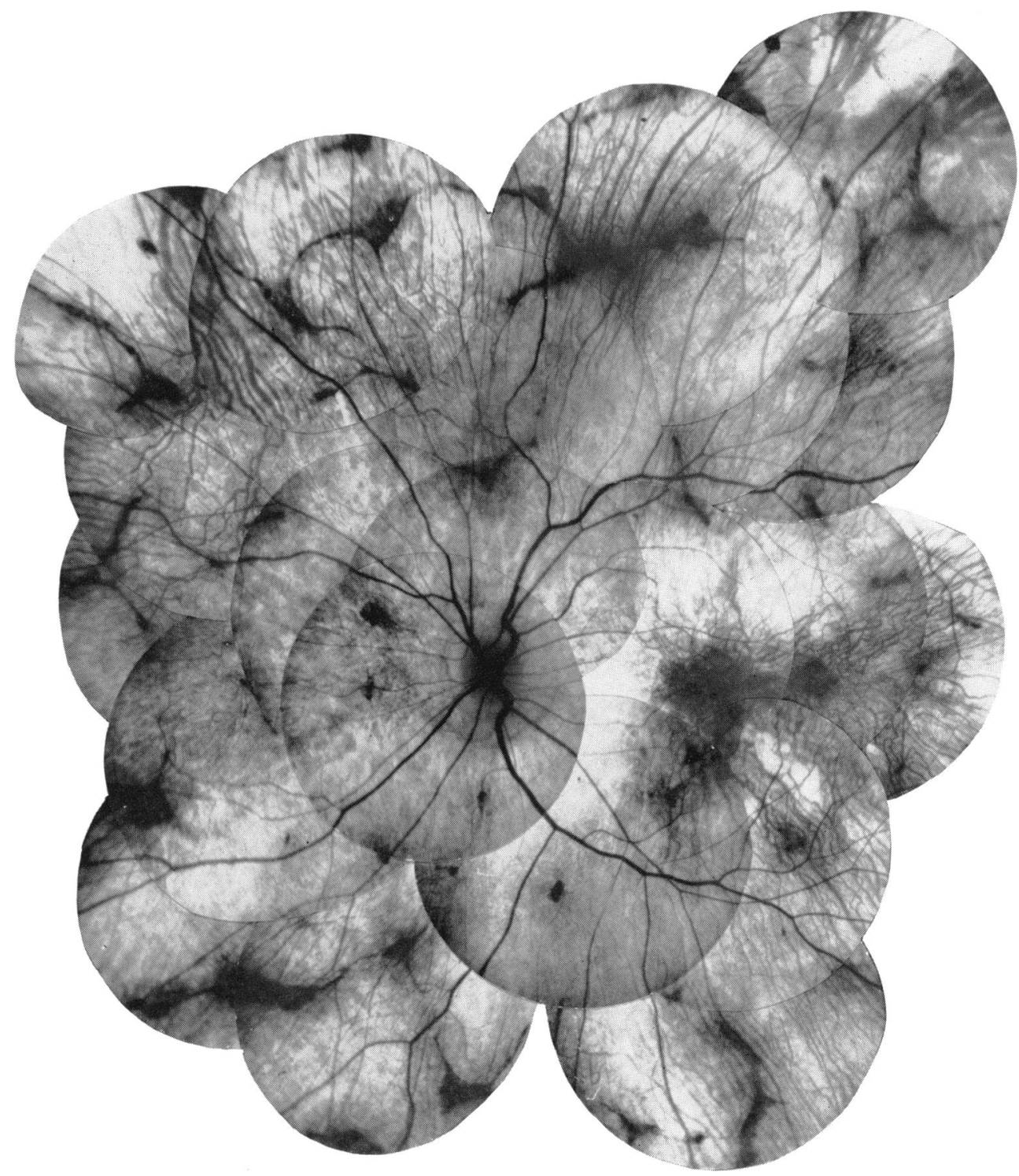

FIG. I Composite photograph of a patient with choroideremia (Pat. I, when he was I2 years old). A marked atrophy of the fundus is present and only the remnants of choroidal vasculature are visible. The vascularization in the macula is better spared. Only some attenuation in the retinal vessels is detectable 
typically seen. At a later stage the wide, diffuse chorio-retinal atrophy (Fig. 2) resembled that of choroideremia. The retinal vessels were extremely narrow. The disc was pink and the vascularity well maintained (Fig. 4). In the macular area and peripheral fundus, an abundance of fine, velvet-like pigment was present, on which glittering crystals were seen. The pigmentation of the macular area was sharply distinguished from the neighbouring atrophic fundus, especially in the fluorescein angiographic studies (Fig. $6 \mathrm{~A}-\mathrm{B}$ ). This pigment was dense enough to obscure the underlying choroidal vessels.

\section{Choroideremia}

A marked choroidal and pigment epithelial diffuse atrophy was seen in the fundus of both patients with choroideremia (Fig. I, p. 25). Remnants of choroidal vasculature were present in the macular area and periphery. Only a few clumps of pigment were present here and there throughout the fundus. The colour of the disc was pink and a degenerative ring was visible around the disc. Some attenuation in retinal vessels was detectable. One of the choroideremic patients (Pat. I) had been examined at our clinic when he was a boy of I 2. At that time atrophy of the fundus was already extensive (Fig. I) and it was of about the same degree during this study (Fig. 2).

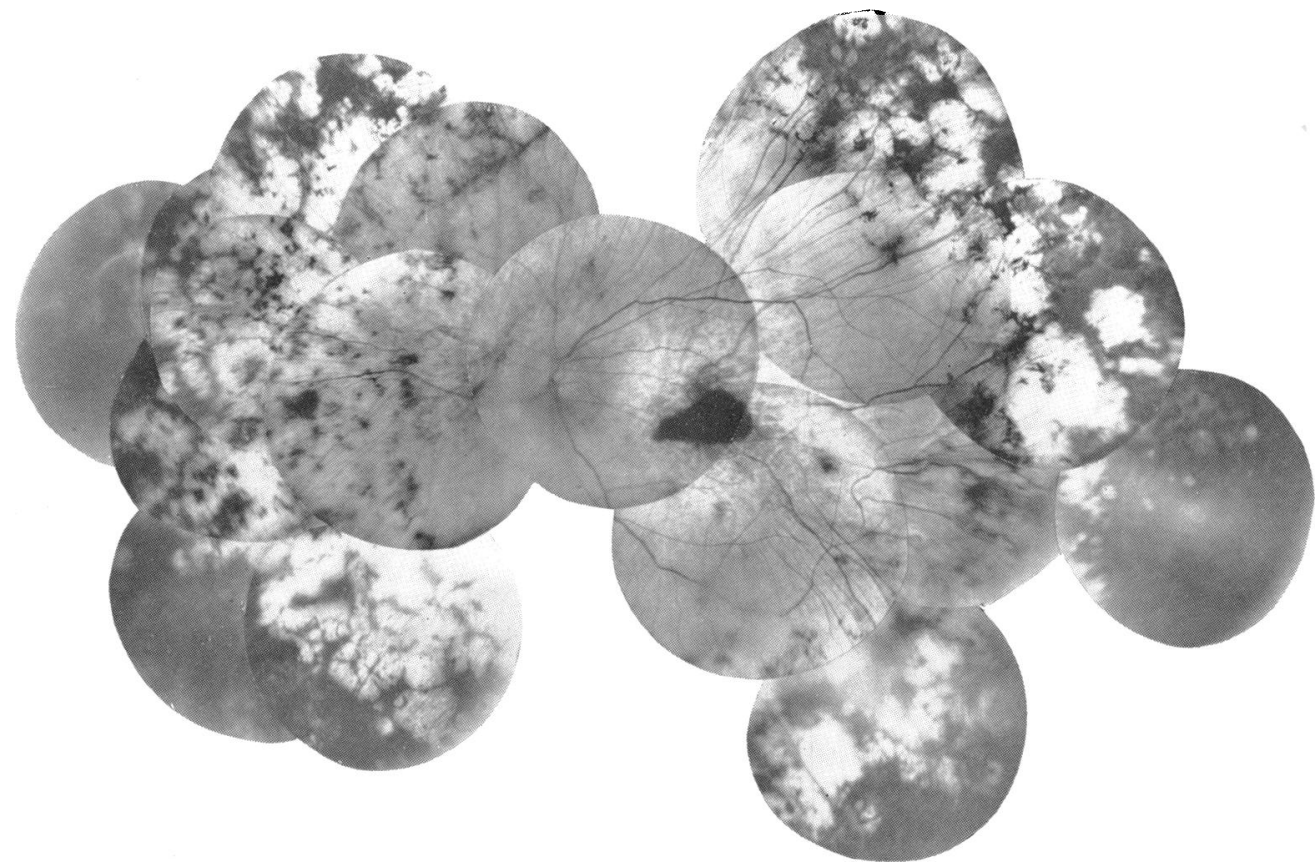

FIG. 2 Composite photograph of a 44-year-old man with gyrate atrophy of the choroid and retina. Note the dense, sharply-defined pigmentation in the macula. An abundance of this fine velvet-like pigmentation is also present at the periphery. In the midperiphery, small atrophic patches are present among the pigmentation. Retinal vessels are extremely attenuated

In the black and white photograph of the papillary area (Fig. 3 A) a degenerative ring around the disc was clearly visible. In the angiographic studies of the papillary area (Fig. 3 B-C), the larger choroidal vessels became clearly visible, showing a marked variation in calibre; some of the vessels were almost closed. No normal choriocapillaris was present. The vascularization in the disc was diminished and retinal vessels showed some attenuation. In the fluorescein angiographic studies of the macular area (Fig. $5 \mathrm{~A}-\mathrm{D}$ ) 
numerous choroidal vessels became visible. In addition to the larger choroidal vessels, some choriocapillaris was also present and all the vessels here were clearly visible without any pigmentation above them. The functioning macular area was not distinguished from the neighbouring atrophic area by any special border. When the dye came out of the functioning choriocapillaris, it diffused freely into the perivascular space (Fig. $5 \mathrm{G}$ ).

Central regional totcl choroidal vascular atrophy

In the fundus of the three patients with GRT, sharply-defined atrophic areas around the disc and in the posterior pole of the fundus were seen (Fig. 7). There was some scattered
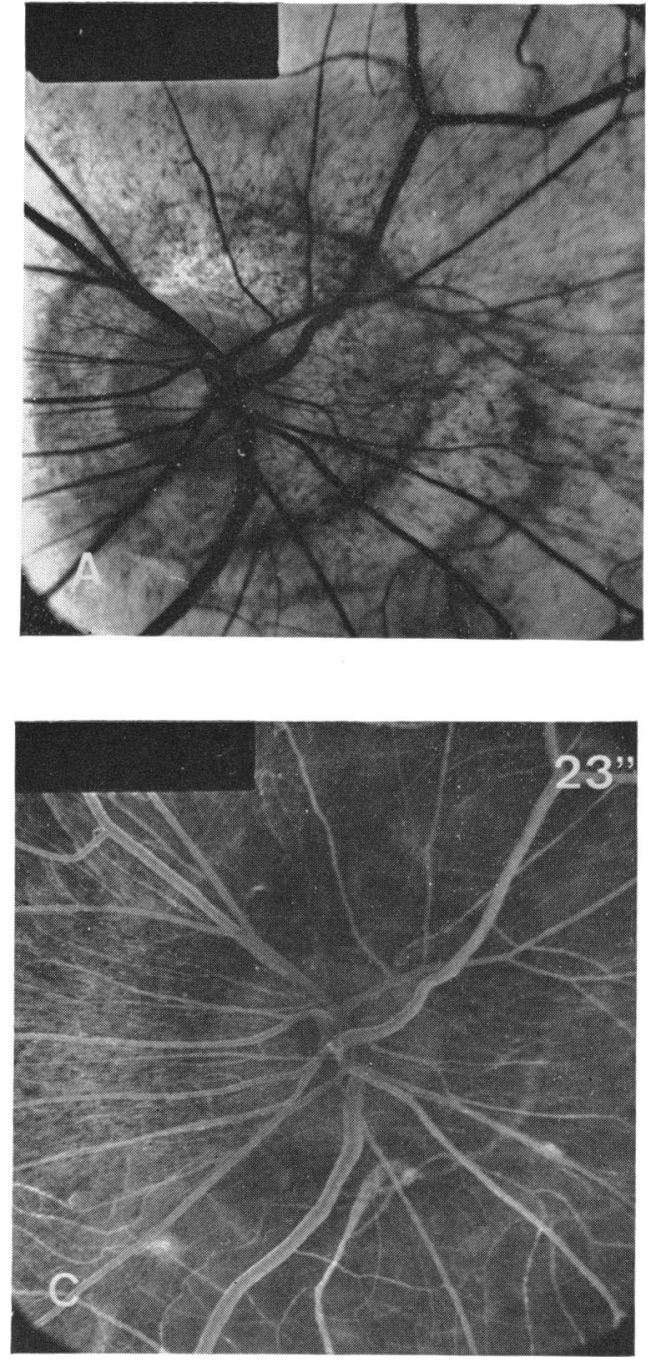

F IG. 3 Fluorescein angiographic studies of a patient with chorcideremia (Pat. 2)

A. Peripapillary degeneration is clearly visible

B and C. Angiograms show the marked variation in calibre of choroidal vessels (arrow). Vascularity in the disc is diminished
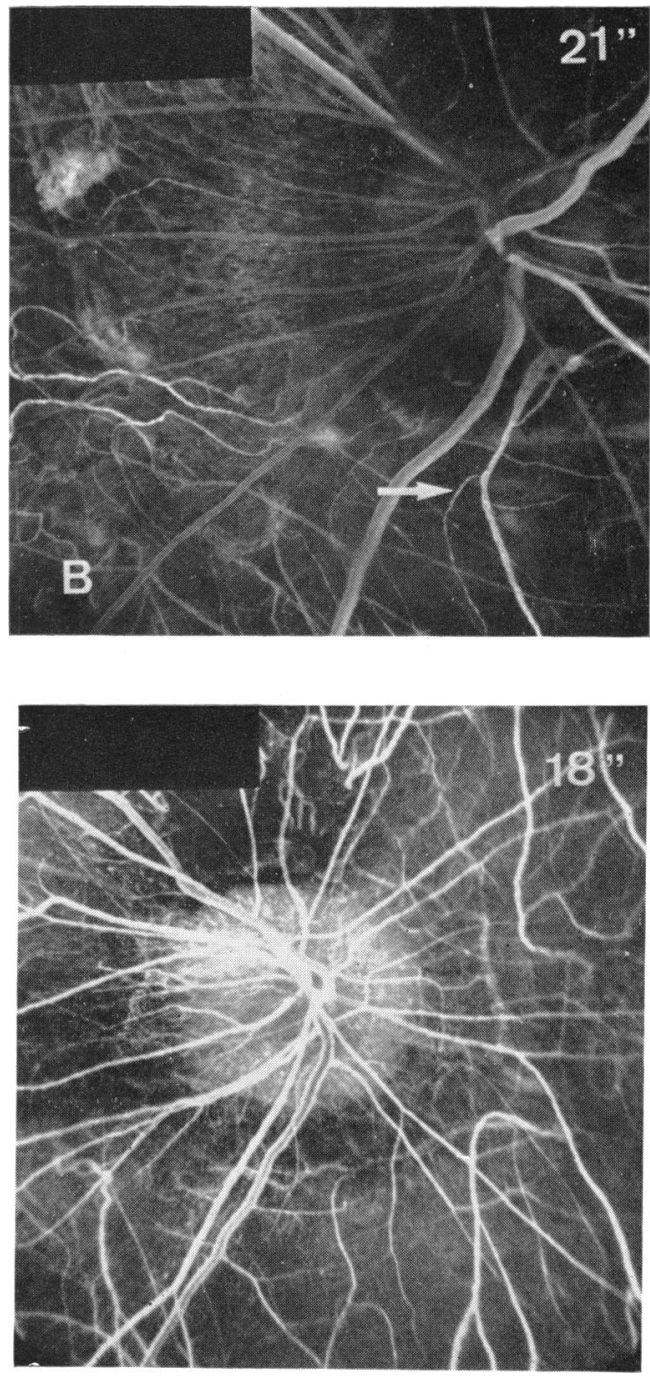

FIG. 4 Fluorescein angiogram of optic disc of same patient as seen in Fig. 2. Note the better vascularization in the disc of this patient with gyrate atrophy of the choroid and retina compared with that of the choroideremic patient 

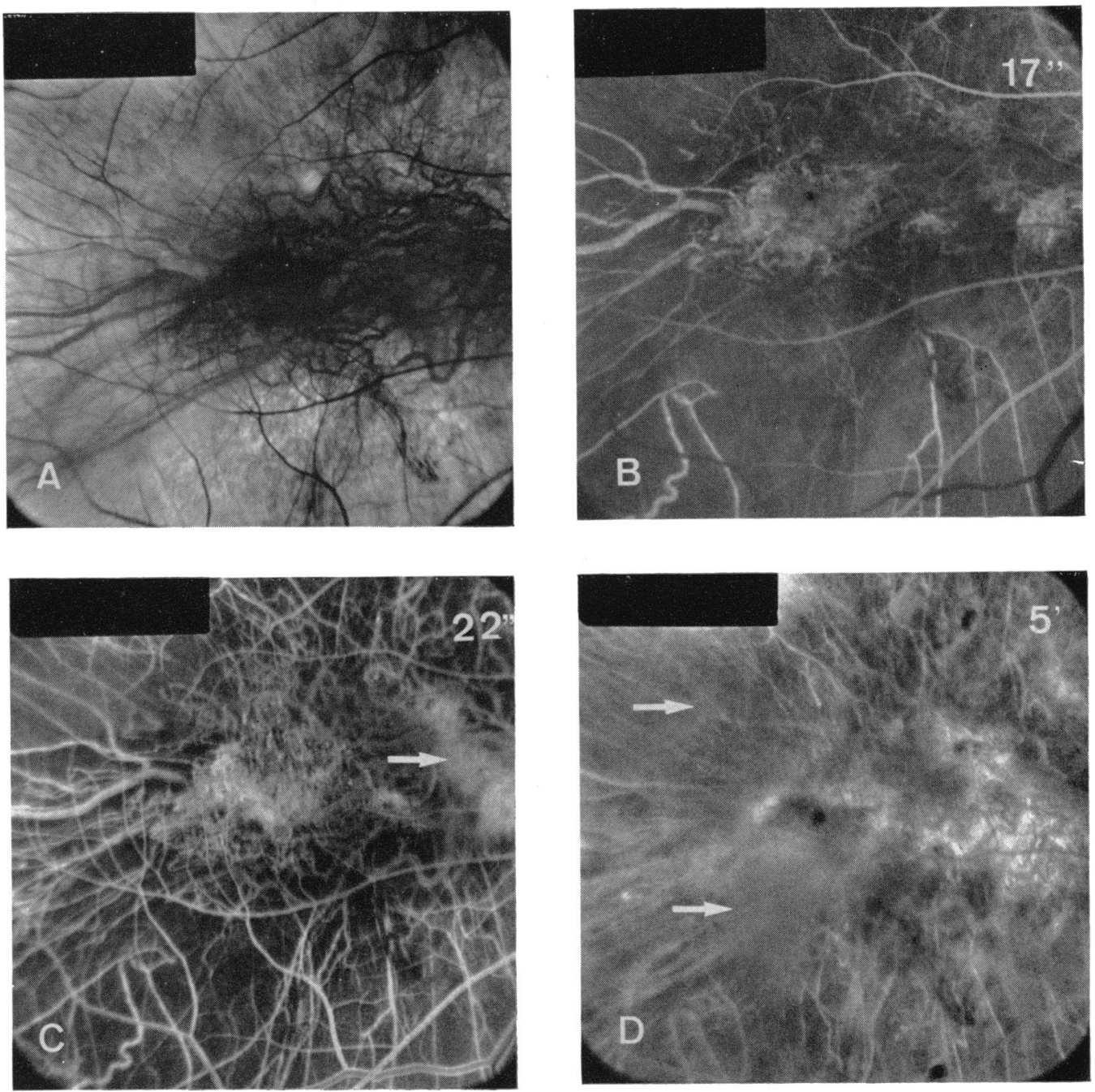

FIG. 5 Fluorescein angiograms in the macular area of a patient with choroideremia (Pat. I)

A. The pre-injection picture of the macula

B. Filling of the functioning choriocapillaris as well as the larger choroidal vessels is visible

C. The choroidal vessels are more clearly visible and no special pigmentation is present. Diffusion of the dye out of the functioning choriocapillaris is visible (arrow)

D. The dye has been absorbed from the functioning choriocapillaris and is still present in the atrophic area area of the fundus (arrows)

pigment in the atrophic areas or around them. The other parts of the fundus also showed some mild dystrophic changes. Some attenuation of the retinal vessels was present.

Fluorescein angiographic studies showed two types of lesions. Gray, oedema-like hyperfluorescence was present in the retinal arterial phase of angiography (Fig. $8 \mathrm{~A}$ ). In the following angiograms this hyperfluorescent area became more clearly visible. When the dye diffused out of the functioning choriocapillaris into the perivascular space, a sharply-defined atrophic area was detectable (Fig. 8 D). After 5 minutes the dye was 

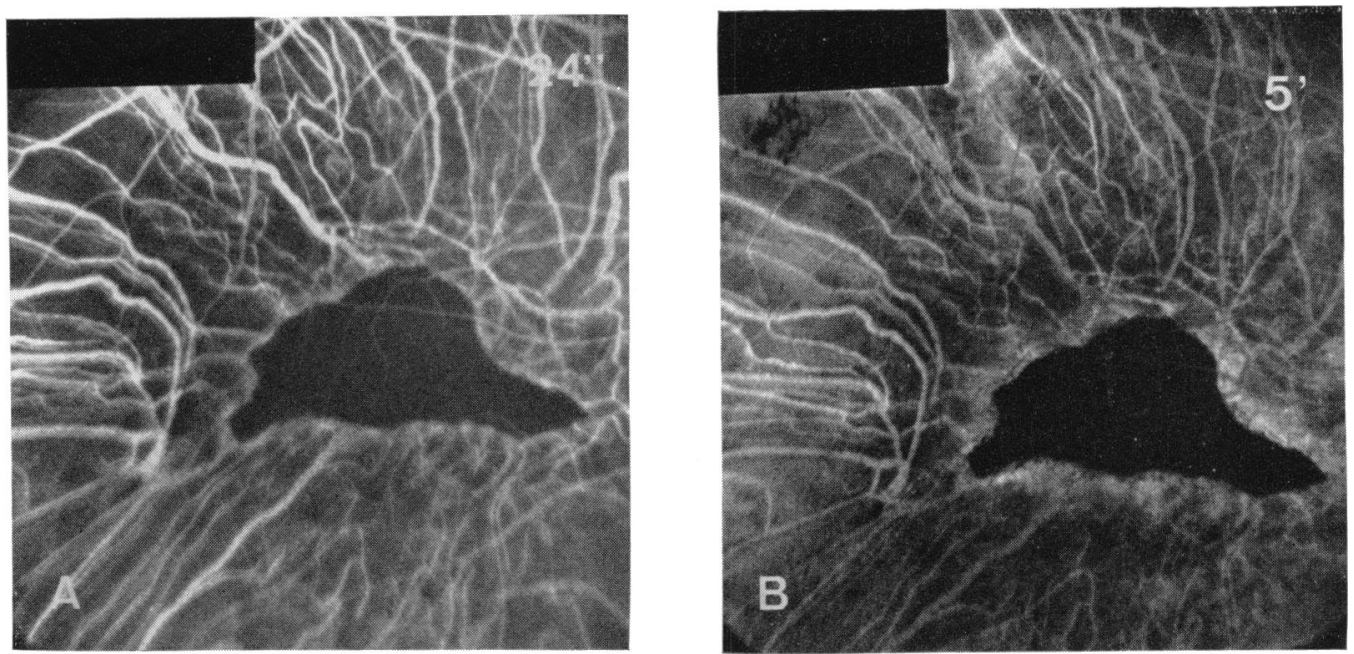

FIG. 6 Fluorescein angiogram of the patient seen in Fig. 2 with gyrate atrophy

A. Dense, sharply-demarcated pigmentation hides all the choroidal vessels from view in the functioning macular area. Only some retinal vessels are visible on this pigmentation

B. An abundance of fine pigment is also present in the 5-minute angiogram. Compare with corresponding picture of a case of choroideremia (Fig. 5 D)

absorbed from the functioning choriocapillaris and was still present in the atrophic choroid (Fig. $8 \mathrm{E}$ ). In the second type of atrophic area (Fig. $8 \mathrm{G}$ no oedema-like fluorescence was present. Diffusion of the dye out of the functioning choriocapillaris was detectable in the sharply-defined demarcation line between the atrophic area and normal functioning retina, and no hyperfluorescence was detectable in the centre of the atrophic area.

In the two types of lesion described, the lesion with oedema-like hyperfluorescence probably represents the primary type in which at least the pigment epithelium is damaged, whereas the other type is a later stage in which no functioning choriocapillaris is present in the centre of the lesion.

RETINAL FUNCTION STUdies (Table II, overleaf).

Choroideremia

Both the patients were myopes. The corrected visual acuity varied from $0 \cdot 15$ to $0 \cdot 5$. Severe constriction in the fields of vision was present with both patients, being under $5^{\circ}$ in all eyes. The dark adaptation showed Type $\mathrm{V}$ curves according to the classification by François, Verriest, and de Rouck (1956). The colour vision of the patients was within normal limits. The ERG was extinguished in both patients and in the EOG examination the patients could not see the fixation lights at all.

\section{Central regional total choroidal vascular atrophy}

Two of the patients with central regional total choroidal vascular atrophy were myopes, while the refraction of the third of these patients was not recordable due to cloudy media. The corrected visual acuity from finger count to $\mathrm{I} \cdot \mathrm{O}$ was present. The peripheral fields of vision were normal in all three patients. Central or paracentral scotomas were detectable corresponding to obviously involved areas of the fundus in all eyes. The dark- 


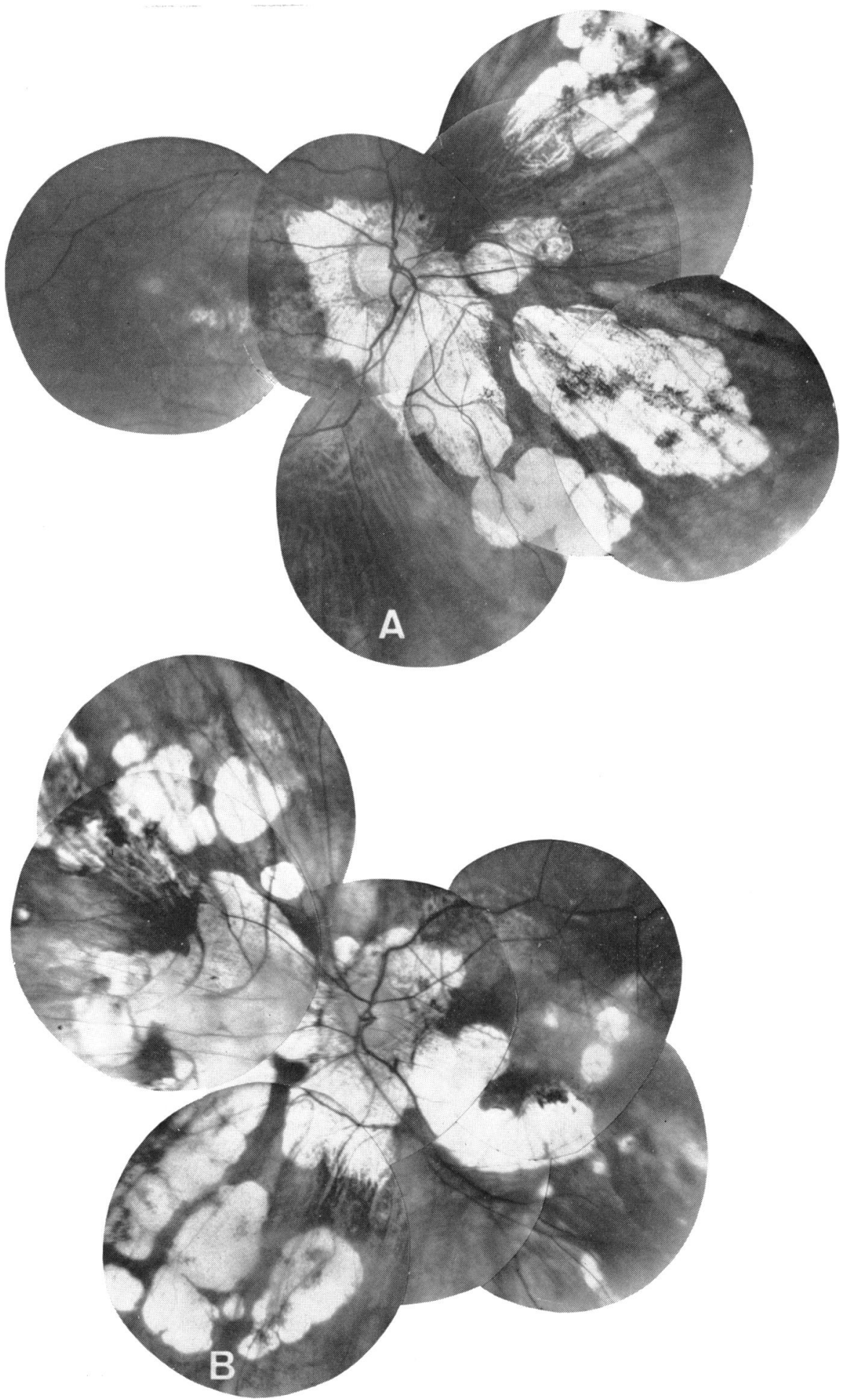

FIG. 7 Composite photograph of a patient with central regional total choroidal vascular atrophy (Pat. 4). The sharply-defined atrophic areas around the disc are located at the posterior pole of the fundus

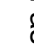

。

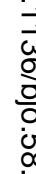

N

을

c 

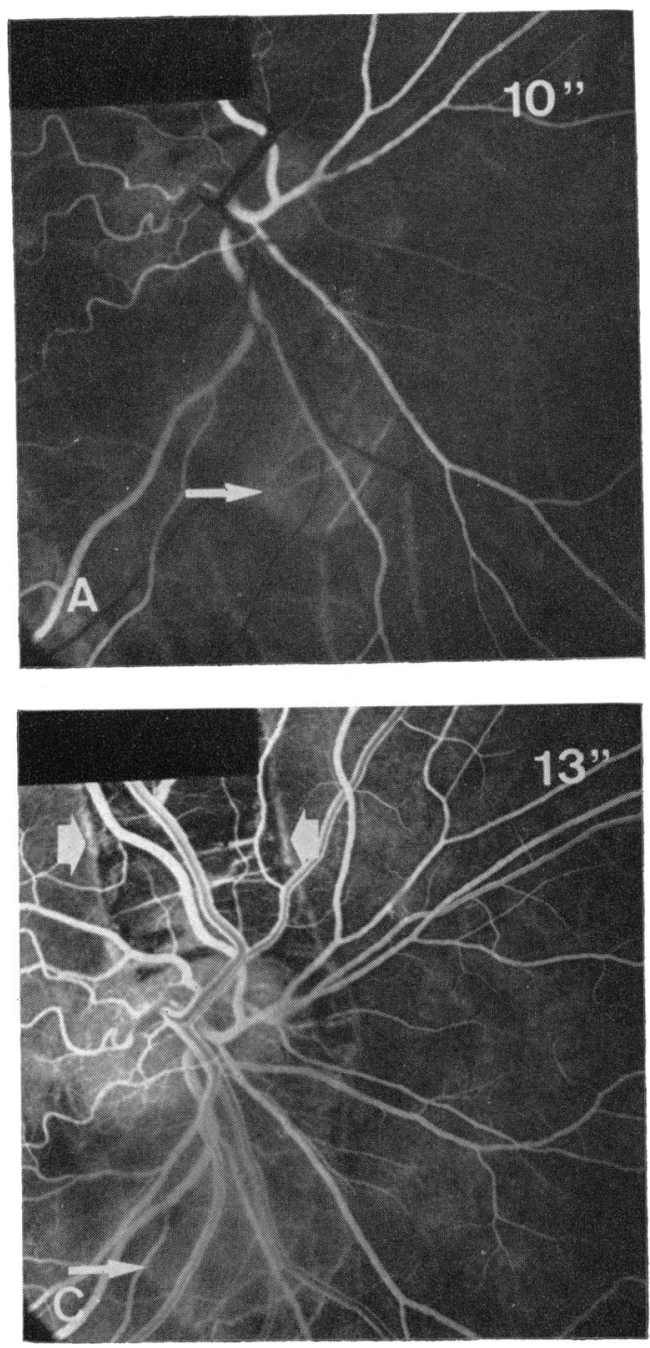

FIG. 8 Fluorescein angiograms of the fundus in the patient with central regional total choroidal vascular atrophy

A. At the retinal arterial phase an oedema-like hyperfluorescence became visible (arrow)

$\mathrm{B}$ and $\mathrm{C}$. In these pictures this oedema-like area is more easily detectable (small arrow). An atrophic area in the centre of which no functioning choriocapillaris is present is seen above the disc (large arrow). A sharply-defined demarcation line becomes visible when the dye diffuses out of the functioning choriocapillaris between the atrophic area and the normal functioning retina

D. The oedema-like area contrasts sharply with the neighbouring area when the dye diffuses out of the choriocapillaris

E. When the dye has been absorbed from the normal functioning choriocapillaris it is still left in the atrophic areas (arrows)
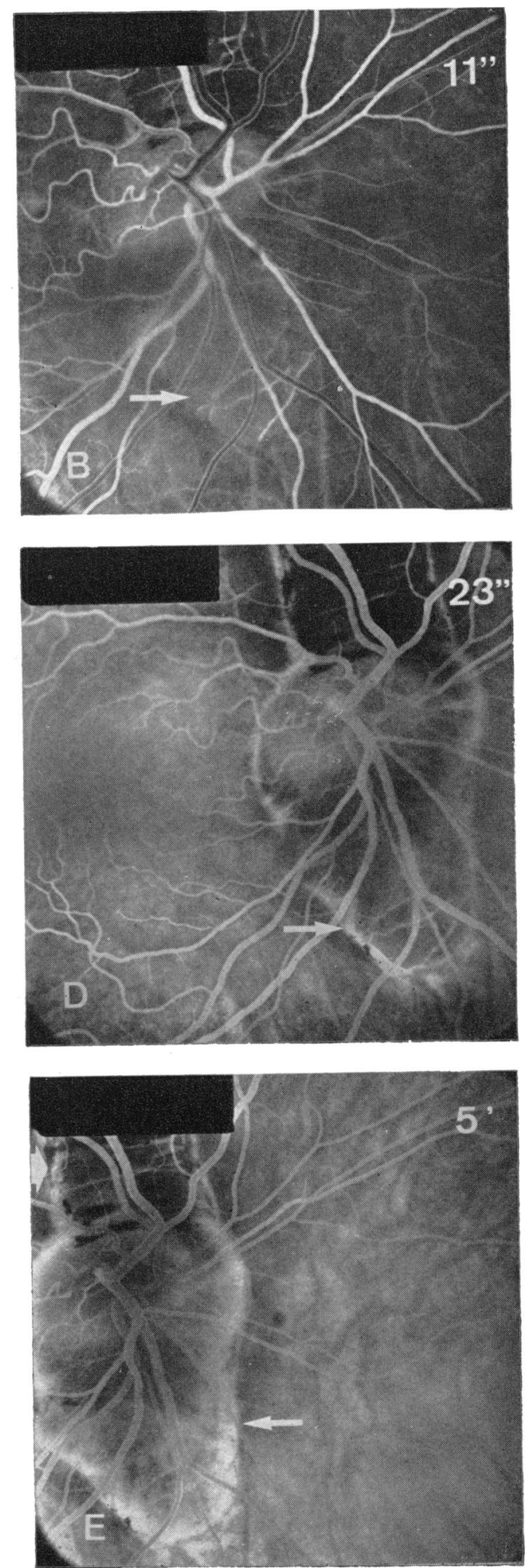
Table II Ophthalmological features in five patients with choroideremia and central regional total choroidal vascular atrophy

\begin{tabular}{|c|c|c|c|c|c|c|c|c|c|c|}
\hline \multirow{2}{*}{$\begin{array}{l}\text { Patient } \\
\text { No. }\end{array}$} & \multicolumn{2}{|l|}{ Refraction } & \multicolumn{2}{|c|}{$\begin{array}{l}\text { Corrected } \\
\text { visual acuity }\end{array}$} & \multirow{2}{*}{ Lens } & \multirow{2}{*}{$\begin{array}{l}\text { Field of } \\
\text { vision }\end{array}$} & \multirow{2}{*}{$E R G$} & \multirow{2}{*}{$E O G$} & \multirow{2}{*}{$\begin{array}{l}\text { Type of } \\
\text { dark } \\
\text { adaplation }\end{array}$} & \multirow{2}{*}{$\begin{array}{l}\text { Colour } \\
\text { vision }\end{array}$} \\
\hline & Right & Left & Right & Left & & & & & & \\
\hline I & $\begin{array}{l}S-7.5 \\
C-3.5\end{array}$ & $\begin{array}{l}S-7 \cdot 5 \\
C-3 \cdot 0\end{array}$ & $0 \cdot 15$ & 0.15 & $\begin{array}{l}\text { Cataract } \\
\text { both }\end{array}$ & $<5^{0}$ both & $\begin{array}{l}\text { Extin- } \\
\text { guished }\end{array}$ & $\begin{array}{l}\text { Not } \\
\text { recordable }\end{array}$ & V & $\begin{array}{l}\text { Within } \\
\text { normal } \\
\text { limits }\end{array}$ \\
\hline 2 & $S-2 \cdot 0$ & $S-2 \cdot 0$ & 0.5 & $0 \cdot 2$ & $\begin{array}{l}\text { Cataract } \\
\text { both }\end{array}$ & $<5^{0}$ both & $\begin{array}{l}\text { Extin- } \\
\text { guished }\end{array}$ & $\begin{array}{l}\text { Not } \\
\text { recordable }\end{array}$ & $\mathrm{V}$ & $\begin{array}{l}\text { Within } \\
\text { normal } \\
\text { limits }\end{array}$ \\
\hline 3 & $\begin{array}{l}S-6 \cdot 5 \\
G-1 \cdot 5\end{array}$ & $S-16 \cdot 0$ & 0.8 & 0.4 & $\begin{array}{l}\text { Almost } \\
\text { clear both }\end{array}$ & $\begin{array}{l}\text { Paracentral } \\
\text { scotoma right } \\
\text { Central sco- } \\
\text { toma left }\end{array}$ & $\begin{array}{l}\text { Normal } \\
\text { right } \\
\text { Subnormal } \\
\text { left }\end{array}$ & Normal & II & Normal \\
\hline 4 & $\begin{array}{l}\overline{S-0.5} \\
\mathrm{C}+3.5\end{array}$ & $\begin{array}{l}S-2 \cdot 0 \\
C+3 \cdot 5\end{array}$ & 0.33 & $1 \cdot 0$ & $\begin{array}{l}\text { Aphakic } \\
\text { both }\end{array}$ & $\begin{array}{l}\text { Central sco- } \\
\text { toma right } \\
\text { Paracentral } \\
\text { scotoma left }\end{array}$ & Subnormal & Normal & II & Normal \\
\hline 5 & Not recor & dable & 0.004 & 0.03 & $\begin{array}{l}\text { Cataract } \\
\text { both }\end{array}$ & $\begin{array}{l}\text { Central sco- } \\
\text { toma both }\end{array}$ & $\begin{array}{l}\text { Not } \\
\text { recordable }\end{array}$ & $\begin{array}{l}\text { Not } \\
\text { recordable }\end{array}$ & II & $\begin{array}{l}\text { No } \\
\text { colour } \\
\text { discri- } \\
\text { mination }\end{array}$ \\
\hline
\end{tabular}

$$
\begin{aligned}
& \mathbf{S}=\text { spherical } \\
& \mathbf{C}=\text { cylindrical }
\end{aligned}
$$

adaptation curves Type II in all three patients was found. The colour vision of two of the patients ( 3 and 4 ) was normal and the third, who had markedly impaired visual acuity, could not discriminate colours at all. The ERG was normal in one eye of Patient 3, subnormal in three eyes (Pat. 3 and 4), and was not recordable in a third patient (5). The EOG examination showed a normal response in two of the patients (Pat. 3 and 4 ) and was not recordable in Patient 5.

\section{OTHER OGULAR EXAMINATION}

\section{Choroideremia}

Round, small, and subcapsular opacities were detectable in the lenses of these two patients. Some stromal diffuse clouding was present in the corneae of one of them (Pat. 2). Filamentous opacities and a few cells were present in the vitreous of both of these patients.

\section{Central regional total choroidal vascular atrophy}

Only a few punctate opacities were seen in the lenses of one of these patients. Dense cataract, especially in the anterior capsule, was present in the lenses of Patient 5. The third patient with this disease had been aphakic since 1958. Filamentous opacities were present in the vitreous of all these patients. A retinal detachment operation was performed successfully in 1966 in the left eye of Patient 3 and a retinal detachment was now present in the right eye of Patient 5.

\section{PLASMA AMINO-AGID ESTIMATION}

All patients with choroideremia and GRT showed normal plasma concentrations of taurine, threonine, serine, glutamine, glycine, alanine, valine, methionine, isoleucine, leucine, tyrosine, phenylalanine, ornithine, lysine, histidine, and arginine. The plasma ornithine concentrations of the patients are shown in Table I. 


\section{Discussion}

The classification of the primary chorio-retinal atrophies recently described by Krill and Archer (197I) was based on the position of the lesion and on the degree of involvement of the different layers of the choroidal vasculature. According to this classification, gyrate atrophy of the choroid and retina is a diffuse total choroidal vascular atrophy with autosomal inheritance. In the earlier study (Takki, I974), all fifteen patients with gyrate atrophy of the choroid and retina showed the typical signs of diffuse total choroidal vascular atrophy. In addition, there were pigment changes around the atrophic areas. Similar scattered pigment changes were also described earlier, i.e. by Kurstjens (1965) and by Krill and Archer (197I). The recent data (Takki, 1974) show that the pigment changes around the atrophic areas include a typical fine, velvet-like pigmentation in the macular area and peripheral retina at a late stage of the disease. These findings are especially clear in fluorescein angiograms as shown in Fig. 6.

In patients with a late stage (IV) of gyrate atrophy of the choroid and retina, glittering crystals were found on the velvet-like pigmentation (Takki, I974). Small, lustrous, white dots were also found in a patient with an atypical tapeto-retinal degeneration (Vannas and Setälä, I958). However, similarity between these spots is hardly probable, since the crystals in gyrate atrophy of the choroid and retina are elongated, and always situated on the velvet-like pigmentation, whereas in the case reported by Vannas and Setälä (1958) the spots were round and lay deeper in the retinal layers, particularly around the retinal veins.

The autosomal inheritance which has been claimed in patients with gyrate atrophy of the choroid and retina (Botermans, 1972) also seems evident in the series mentioned and will be described in detail elsewhere (Takki and Simell, to be published).

According to Krill and Archer (197I), the second type of diffuse total choroidal vascular atrophy is X-linked and is designated choroideremia. In this condition the visual acuity is diminished earlier in life and only males are affected. In the present study both patients with choroideremia were male and they revealed the signs of a late stage of the disease with markedly diminished visual acuity. Poor visual acuity had already been recorded in one of them at the age of 12 years. The mean age of the patients at the late stage (IV) of gyrate atrophy was 43 years (Takki, 1974). In the present late stage of choroideremia only a few clumps of pigment were scattered throughout the fundus. These findings are in accordance with the description of Franceschetti and others (1963), Kurstjens (1965), and McGulloch (1969), and present a different fundus picture from that seen in patients with gyrate atrophy of the choroid and retina, who showed a dense, velvet-like, fine pigmentation in the macula and peripheral retina at late stage of the disease. This difference in pigmentation is especially marked in fluorescein angiographic studies. In fluorescein angiograms in patients with choroideremia at an advanced stage (Krill and others, I968; Hyvärinen and others, I969; Gass, 1970), intense fluorescence was seen in the central functioning area of the fundus, indicating normal function of choriocapillaris here. The filling of the greater choroidal vessels also became clearly visible and only some pigment was observed in this central area. In the present fluorescein angiograms in patients with choroideremia, the choroidal vessels in the macular area are also clearly visible (Fig. 5 A-D), whereas in gyrate atrophy the choroidal vessels in the macular area are hidden beneath the dense pigmentation, which is sharply demarcated against the diffuse atrophic area of the fundus (Fig. $6 \mathrm{~A}-\mathrm{B}$ ). Histological findings in choroideremia show no special 
pigmentation in the macular area (Vogel, 1972). The histology of gyrate atrophy of the choroid and retina is not yet known. The glittering crystals seen in gyrate atrophy were not found in patients with choroideremia.

The third type of total choroidal vascular atrophy is regional (Krill and Archer, 1971) and is also called central gyrate atrophy (Franceschetti and others, I 963). In this disease the atrophic areas are located in the posterior pole spreading towards the periphery. Affection of the posterior pole and spread towards the periphery were also seen in the present cases of CRT. These two features in the development of the fundus changes differ from the development of gyrate atrophy (Takki, 1974), in which the convex margins of the atrophic areas always spread from the midperiphery towards the posterior pole. Furthermore, the earliest change, a homogeneous, grey, oedema-like appearance of the involved retina in GRT (Krill and Archer, I97I), was also detectable in the present study (Fig. 8 A-C). The present fundus changes with an absence of velvet-like pigmentation and glittering crystals in this disease, characteristics in the late stage of gyrate atrophy of the choroid and retina, suggest that the posterior gyrate atrophy described by Franceschetti and others $(1963)$ is a different condition from gyrate atrophy of the choroid and retina. This opinion is further supported by the present normal values of plasma ornithine concentration in GRT.

The previous study concerning the patients with gyrate atrophy of the choroid and retina suggested that the primary lesion was situated at the level of the pigment epithelium - the choriocapillaris (Takki, I974). This suggestion was dependent on the fluorescein angiographic studies, the ERG, the EOG, dark adaptation, colour vision, and the visual fields. In the present study similar defective function in the retinal function tests in patients with choroideremia was recorded. The constant relationship between gyrate atrophy and hyperornithinaemia suggests a metabolic defect as the basis of changes in gyrate atrophy (Simell and Takki, 1973; Takki, 1974) and, because similar defective retinal functions are present in choroideremia, a defect in protein metabolism may also be present in this disease although the plasma amino-acids are normal.

The funduscopic picture, results of fluorescein angiographic studies, and retinal function tests in patients with GRT differ from those obtained in gyrate atrophy and choroideremia. No suggestion on this basis can be put forward for the aetiology of GRT.

\section{Summary}

Two patients with choroideremia and three patients with central regional total choroidal vascular atrophy (CRT) were studied by fluorescein angiography, retinal function tests, and plasma amino-acid estimation. The results were compared with those obtained earlier in gyrate atrophy of the choroid and retina. Fine, dense, velvet-like pigmentation, on which glittering crystals are situated, in the macula and peripheral retina were observed to be typical in gyrate atrophy at a late stage of the disease; this pigmentation was lacking in choroideremia although the retinal function tests are similarly defective in both diseases. The fundus changes, as well as retinal function tests, in GRT were different from those in gyrate atrophy or choroideremia. Hyperornithinaemia, which is constantly present in gyrate atrophy, was lacking in choroideremia and of CRT.

I should like to thank Prof. Salme Vannas for referring one patient with central regional total choroidal vascular atrophy. 


\section{References}

AmalRic, P. (1969) Bull. Soc. Ophtal. Fr., numéro spécial, p. I 89

Botermans, c. H. G. (1972) In "Handbook of Clinical Neurology", ed. P. J. Vinken and G. W.

Bruyn, vol. 13 "Neuroretinal degenerations", pp. 253, 256. North Holland Publishing,

Amsterdam

FRANCESCHETTI, A., FRANÇOIs, J., and BABEL, J. (1963) "Les hérédo-dégénérescences choriorétiniennes", vol. 2, p. 647 . Masson, Paris

FRANÇOIs, J. (1958) A.M.A. Arch. Ophthal., 59, 88

-, VERRIEST, G., and DE ROUCK, A. (1956) Ophthalmologica (Basel), Suppl. 43

GASS, J. D. M. (1970) In "Stereoscopic Atlas of Macular diseases", p. i Io. Mosby, St. Louis hYVÄRINEN, L., MAUMeneE, A. E., GeORge, T., and weinstein, G. w. (1969) Amer. F. Ophthal., 67, 653 KRILL, A. E., and ARCHER, D. (197I) Amer. F. Ophthal., 72, 562

-, NEWELL, F. W., and CHISHTI, M. I. (I968) Ibid., 66, 470

KURSTJENS, J. H. (1965) Docum. ophthal. (Den Haag), 19, I

MCGUlloch, G. (1969) Trans. Amer. ophthal. Soc., 67, I42

SIMELL, o., and TAKKI, K. (1973) Lancet, I, I03 I

soupart, P. (1962) In "Amino Acid Pools", ed. J. T. Holden, p. 233. Elsevier, Amsterdam

SORSBY, A., FRANCESChETTI, A., JOSEPH, R., and DAVEY, J. (1952) Brit. F. Ophthal., 36, 547

SPACKMAN, D. H., Stein, W. H., and moore, s. J. (1958) Analyt. Chem., 30, i 190

TAKKI, K. (1974) Ibid., 58, 3

vANNAS, s., and SETÄLÄ, м. (1958) Acta ophthal (Kbh.), 36, 849

VOGEL, M. H. (1972) European Ophthalmic Pathology Society IIth Ann. Meeting, Helsinki June, 8-10, I972

WAARdenburg, P. J. (1959) “Acta XVIII Conc. Ophthal. Belg., I958”, vol. 2, p. I 578

- FRANCESGhetti, A., and KLEIN, D. (196I) "Genetics and Ophthalmology", vol. I, p. 8oo, Royal Van Gorcum, Assen, The Netherlands

$\longrightarrow, \longrightarrow$ - $\longrightarrow$ (1963) Idem, vol. 2, p. I $583^{2}$ 